\title{
OECD Ülkelerinde Kurumsal Kalite ve Gelir Eşitsizliği İlişkisi
}

\author{
Mehmet AVCI, Turkey; e-mail: mehmetavci.beu@gmail.com \\ Gizem MUKIYEN AVCI, Department of Economics, Faculty of Economics and Administrative Sciences, Bulent \\ Ecevit University, Turkey; e-mail: gizem_avci@beun.edu.tr
}

\section{Institutional Quality and Income Inequality Relationship for OECD Countries}

\begin{abstract}
Income inequality has shown as one of the most important economic problem now. Behind individual specific, economic, social, political factors, also institutional factors effect income inequality. Lower income inequality has expected with higher institutional quality. This study investigates the relationship between institutional quality and income inequality in 23 OECD countries, using fixed and random panel estimation approach and annual data over the period of 1984-2011. Evidence from a panel data estimation shows that a negative relationship between institutional quality and income inequality exist. According to this result, institutional quality is an essential tool for reducing income inequality.

Keywords : Institutional Quality, Income Inequality, Gini, Panel Data, OECD.

JEL Classification Codes : $\quad$ D31, EO2, E24, O15.

$\ddot{\mathbf{O} z}$

Gelir eşitsizliği günümüzün en önemli iktisadi konularından birisi olarak gösterilmektedir. Bireye özgü, iktisadi, sosyal ve siyasi faktörlerin yanı sıra kurumsal faktörler de gelir eşitsizliği üzerinde etkilidir. Daha iyi kurumsal kaliteye sahip olan ülkelerde daha düşük gelir eşitsizliği beklenmektedir. Bu çalışmada kurumsal kalite ve gelir eşitsizliği ilişkisi 23 OECD ülkesinde 19842011 periyodu için sabit ve rassal etkiler modeli ile araştırılmaktadır. Elde edilen sonuçlara göre kurumsal kalite ile gelir eşitsizliği arasında negatif bir ilişki söz konusudur. Buna göre kurumsal kalite gelir eşitsizliğinin azaltılmasında önemli bir araçtır.
\end{abstract}

Anahtar Sözcükler $\quad$ : Kurumlar, Gelir Eşitsizliği, Gini, Panel Veri, OECD. 


\section{Giriş}

Önemli olan iktisadi büyümenin sağlanması mı yoksa büyüme neticesinde ortaya çıkan gelirin eşit paylaşılması mıdır? Yoksa her ikisi de önemli midir ya da birisi diğerine tercih edilmeli midir? Refah iktisadı gelir dağılımı üzerine odaklanırken, modern iktisat teorileri daha çok iktisadi büyüme üzerine odaklanmakta ve büyümenin zaman içerisinde gelir dağılımı eşitsizliğini azaltacağı ifade edilmektedir. Ancak günümüzde birçok gelişmiş ülkede dahi gelir eşitsizliği sorunu ile karşılaşılmaktadır. Söz konusu gelir eşitsizliğinin artmasında küreselleşme, teknolojik değişim, iktisadi, sosyal, siyasi ve kurumsal faktörler etkili olmaktadır.

20. yüzyılda kurumsal iktisadi görüş ile ilgili yaşanan gelişmeler, özellikle iktisadi büyüme odaklı çalışmalarda büyümenin dinamikleri arasında kurumsal faktörlerin ön plana çıkmasına yol açmıştır. Bu görüş çerçevesinde kurumsal faktörlerin, ülkeler arasındaki büyüme farklılıklarının açıklanmasında önemli bir role sahip olduğu savunulmaktadır. Kurumlar ve iktisadi büyüme arasındaki ilişkiyi ele alan çalışmalar incelendiğinde genel olarak kurumsal kalite ile ekonomik büyüme arasında pozitif bir ilişki olduğu sonucuna ulaşılmaktadır. Kurumların iktisadi büyüme üzerindeki olumlu etkisinin yanı sıra gelir eşitsizliği üzerinde de etkisi bulunmaktadır. Kurumsal kalitenin daha yüksek (düşük) olduğu ülkelerde gelir eşitsizliğinin daha düşük (yüksek) olması beklenmektedir. Gelir dağılımının daha eşit olması toplumsal refah açısından önem taşımaktadır. Sosyal barışın ve huzurun sağlanabilmesi, siyasi ve iktisadi istikrarın sürdürülebilmesi açısından gelir eşitsizliğini azaltmak devletlerin önemli görevleri arasında sayılmaktadır.

$\mathrm{Bu}$ çalışmada 23 OECD ülkesinde kurumların gelir eşitsizliği üzerindeki etkisi incelenmiştir. Çalışmanın temel hipotezi kurumsal kalite düzeyi arttıkça gelir eşitsizliği azalmaktadır şeklinde kurulmuştur. Çalışmada öncelikle kurumsal kalite ve gelir eşitsizliği teorik çerçevede ele alınmakta, ardından OECD ülkelerinde son yıllardaki gelir eşitsizliğine ilişkin trend ve kurumsal kalite gelir eşitsizliğine ilişkin literatür incelenmekte ve son olarak çalışmanın modeli tahmin edilmekte ve sonuçları analiz edilmektedir.

\section{Kurumsal Kalite ve Gelir Eşitsizliği}

Gelir dağılımı, bir ülkede belirli bir zamanda ortaya çıkan ulusal gelirin, bireyler, gruplar ya da üretim faktörleri arasında bölüşülmesi olarak ifade edilmektedir. Gelir dağılımı sosyal, iktisadi, siyasi ve kurumsal yönleri bulunan çok boyutlu bir olgudur. Gelirin eşit bir şekilde dağılmaması günümüzün en önemli sorunlarından birisidir. En gelişmiş ülkelerde dahi gelirin eşit bir şekilde bölüşülmediği, toplumun bazılarının diğerlerine göre daha yüksek bir refah seviyesine sahip olduğu görülmektedir. Söz konusu eşitsizliğin ortaya çıkmasında; bireylerin doğuştan ve/veya sonradan elde ettikleri yetenekler, şans, risk alma gibi bireye özgü faktörlerin yanında iktisadi, sosyal, siyasi ve kurumsal faktörler de etkili olmaktadir.

Kuznets (1955)'e göre gelir eşitsizliği iktisadi büyüme ve kalkınma ile yakından ilgili olup, büyüme ile birlikte gelir eşitsizliği önce artmakta sonrasında ise azalmaktadır. Bir 
başka ifade ile büyüme ile gelir eşitsizliği arasında ters U ilişkisi söz konusudur. Gelir eşitsizliğinin artmasında küreselleşme, ticari entegrasyonun artması, doğrudan yabancı yatırımlar ve teknolojik gelişme de etkili olmuştur. Ülkelerin dışa açılması ile birlikte özellikle teknolojiye adaptasyonun sağlanabilmesi açısından nitelikli işgücüne yönelik talep artışı gelirin söz konusu özelliklere sahip bireyler lehine gelişmesini sağlamıştır.

Gelir eşitsizliği üzerinde etkili olan bir diğer faktör ülkenin kurumsal yapısıdır. Son yıllarda özellikle iktisadi büyüme ile ilişkisi bakımından kurumların önem kazandığı görülmektedir. North (1990: 3) kurumları, iktisadi ve sosyal davranışları yöneten formel ve enformel kurallar olarak tanımlamakta ve kurumların ülkenin kültürünü ve tarihini yansıttığını ifade etmektedir. Kurumlar en basit haliyle bireylerin, firmaların ve diğer karar alma birimlerinin tercihlerini tanımlayan kurallar ve davranış kalıpları olarak ifade edilmektedir (Kama, 2016: 20). Kurumlar her toplum için tarihsel süreç içerisinde ortaya çıkmış, değiştirilmesi kolay olmayan ve iktisadi ve/veya iktisadi olmayan kararların alınmasında etkili olan kurallardır. Kurumlar formel ve enformel kurumlar olarak ikiye ayrılmakta olup, ilkinde hukuk kuralları ve anayasal kurallar yer alırken ikincisinde ise tarihten gelen davranış kalıpları, gelenek ve görenekler yer almaktadır.

Kurumların ekonomik performans üzerinde olumlu bir etki meydana getirdiği yapılan çalışmalarda ifade edilmektedir (North, 1994; Knack \& Keefer, 1995; Olson, 1996; Salai-Martin, 1997; Rodrik, 1997; Acemoğlu vd., 2005; Acemoğlu, 2009; Acemoğlu \& Robinson, 2012; Rodrik, 2012). İktisadi büyüme literatüründe kurumların kabul görmesi üç farklı gelişme sonucunda gerçekleşmiştir (Rodrik, 2009: 158). Birincisi Rusya'da destekleyici ve düzenleyici yasal ve siyasi yap1 olmadan uygulanan fiyat reformu ve özelleştirmelerin başarısız olması, ikincisi Latin Amerika'da sosyal sigorta ve güvenlik ağlarına dikkat edilmeden uygulanan piyasa yönelimli reformların yavaş ilerlemesi ve üçüncüsü ise finansal serbestleşmenin finansal düzenlemelerin önüne geçmesi nedeni ile yaşanan Asya krizidir. Bu gelişmeler ile birlikte kurumsal yapının zayıflığı uygulanan politikaların başarısı önünde bir engel olarak görülmektedir.

Kurumlar, bir ülkedeki gelir dağılımı üzerinde de etkilidir. Ülkeler arasındaki gelir farklılıklarının yaşanması ve milli gelir artışları ile ülke içindeki gelir eşitsizlikleri arasındaki ilişkinin Kuznets'in çan eğrisinin tersine bir U eğrisi izlemeye başlaması kurumların gelir eşitsizliği açısından da önemli bir faktör olduğunu ortaya koymaktadır (Uğur, 2011: 36). Piketty ve Saez (2014: 842) de gelir eşitsizliğinin deterministik bir süreç izlemediğini ve bu bağlamda Kuznets'in yanıldığını savunmaktadır. Gelir eşitsizliğinin yönünü belirleyen daha güçlü unsurlar bulunmakta olup, bunlar kurumlar ve toplumun benimsediği ilkelerdir ve ülkelere özgü kurumlar ve tarihsel koşullar gelir eşitsizliği farklılıklarının ortaya çıkmasında etkili bir unsur olarak değerlendirilmektedir (Piketty \& Saez, 2014: 838).

Kurumların etkin bir şekilde işleyebilmesi ve kuralların seçiminde tercihlerin doğru ve uygulanabilir olması kurumsal kalite kavramının çerçevesini oluşturmaktadır (Teyyare, 2013: 75). Bu bağlamda kurumsal kalitesi daha yüksek olan ülkelerde gelir eşitsizliğinin daha düşük olması beklenmektedir. Hükümetlerin sınırsız karar alma yetkisine sahip olduğu, mülkiyet haklarının korunmadığı, yolsuzluğun yüksek olduğu ve kuralların uygulanmadığı 
bir toplumda kurumsal kalite düşmekte ve bu da hizmet sunumunda ve kaynakların bölüşümünde etkinsizliklere neden olmaktadır (Chong \& Calderon, 2000: 761). Stiglitz (2015) standart iktisat teorisinin gelir eşitsizliğini tek başına açıklayamayacağını ve formel kurumların yanı sıra sosyal görenekler gibi informel kurumların da gelir eşitsizliği üzerinde etkisinin olacağını ifade etmektedir. Son yıllarda kurumların gelir dağılımı ve gelir eşitsizliği bakımından önemli bir konu haline gelmesinde özellikle politik kurumlar ile yolsuzlukların gelir dağılımı ile ilişkisi etkili olmuştur (Zhuang vd., 2010: 12).

Kurumsal bir gösterge olarak yolsuzluk gelir eşitsizliği üzerinde olumsuz bir etkiye sahiptir. Yolsuzluk özellikle yoksullar aleyhine etkili olmakta ve gelir eşitsizliğini; düşük ekonomik büyüme, azalan oranlı vergi yapısı, sosyal harcamaların azalışı, beşeri sermaye için yatırımın engellenmesi ve servet dağılımında eşitsizlik gibi kanallar ile arttırmaktadır (World Bank, 2002: 168). Yolsuzluk kamu gelirlerinde azaltıcı bir etkiye sahip olup, bu durum vergi idaresinin etkinliğini azaltmakta, vergi sistemindeki artan oranlılığın derecesini düşürmekte ve vergi adaletini olumsuz yönde etkilemektedir (Dökmen, 2012: 44). Yolsuzluğun alternatif maliyeti sosyal anlamda iyileşmeyi sağlayacak olan eğitim ve sağlık gibi harcamaların azalmasıdır (Gupta vd., 2002). Eğitim harcamalarının daha adil bir gelir dağılımını ortaya çıkardığı bilinmektedir (Gregorio \& Lee, 2002, Sylwester, 2002; Yardımcıoğlu, 2008; Abdullah vd., 2015).

Yolsuzluk, kaynakların özellikle de insan kaynaklarının üretken alanlardan rant kollama faaliyetlerine doğru yönlendirilmesine neden olmaktadır (Shleifer \& Vishny, 1993; Gupta vd., 2002). Öte yandan yolsuzluk, devletin gelir dağılımında adaleti sağlamak üzere yeniden dağıtıcı rolünü de olumsuz yönde etkilemektedir (Tanzi, 1998). Bu bağlamda kurumsal bir gösterge olarak yolsuzluğun gelir eşitsizliğini arttırıcı yönde bir etkisi bulunmaktadır (Johnstan, 1989; Hindriks vd., 1999; Chong \& Goldstein, 2004; GyimahBrempong \& Camacho, 2006; Dinçel \& Günalp, 2008; Johanssun, 2013). Gelir eşitsizliğinin artması, aynı zamanda büyümenin yavaşlaması ve suçların artmasına dayalı olarak toplumsal huzursuzluğun ve kaygının ortaya çıkmasına da neden olmaktadır (Barro, 2000; Perera \& Lee, 2013).

\section{Literatür}

Bu kısımda öncelikle kurumsal kalite ile gelir eşitsizliği arasındaki ilişkiye yönelik ampirik literatüre yer verilmektedir. Literatürdeki çalışmaların daha çok kurumsal kalite göstergeleri ile gelir eşitsizliği arasında olduğu görülmektedir. Bu bağlamda özellikle yolsuzluk ve gelir eşitsizliği üzerine odaklanıldığı görülmektedir.

Chong ve Calderon (2000) çalışmasında kurumsal kalite ile Gini katsayısı arasında quadratik bir ilişki tespit etmiştir. Özellikle kurumsal kalitesi daha iyi olan ülkelerde kurumsal kalite ile Gini katsayısı arasında negatif bir ilişki söz konusu iken kurumsal kalitesi düşük olan ülkelerde ise değişkenler arasında pozitif bir ilişki söz konusudur. Çalışmada ele alınan ülkelerde kayıt dışı ekonomiden geçinen bir kesimin olması nedeniyle kurumsal kalitenin artışı bazı kesimlerin gelirlerinde azalışa yol açacak bu da kurumsal kalitenin belli bir zamana kadar gelir eşitsizliğini arttırmasına neden olacaktır. 
Barro (2000) çalışmasında kurumsal kalite göstergelerinden birisi olarak hukuk ve düzen ile Gini katsayısı arasındaki ilişkiyi incelemiş ve değişkenler arasında negatif bir ilişki tespit etmiştir. Buna göre yasaların tarafsız ve güçlü olduğu, gözetildiği ve yasalara uygun hareket edildiği durumda gelir eşitsizliği azalmaktadır.

Yolsuzluk ve Gini katsayısı arasındaki ilişkiyi inceleyen bir diğer çalışmada Li vd. (2000) kuadratik bir ilişki tespit etmiş olup, orta düzeyde yolsuzluk olan ülkelerde Gini katsayısı en yüksek değere, düşük ve yüksek yolsuzluk oranlarının olduğu ülkelerde Gini katsayısı daha düşük değere sahip olduğu sonucuna ulaşılmıştır.

Acemoğlu (2003) çalışmasında ABD, İngiltere ve Kıta Avrupa'sında gelir eşitsizliklerine ilişkin trendi incelemiş ve son birkaç on yılda gelir eşitsizliğinin ABD ve İngiltere'de artışına karşın Kıta Avrupası'nda artmadığını tespit etmiştir. Bu durumu ise; Avrupa'da emek piyasasındaki kurumların, ücret artışları üzerindeki baskısı ve düşük donanımlı işçilerin üretiminin arttırılmasında teknolojik yatırımları daha fazla teşvik etmesi ile açıklamaktadır. Benzer bir şekilde Alderson ve Nielson (2002) tarafından da işgücü piyasası kurumlarının özellikle küreselleşmenin gelir eşitsizliğini arttırıcı etkisini kontrol altına almak üzere önemli olduğu ifade edilmektedir (Alderson \& Nielson, 2002: 19).

Chong ve Gradstein (2004) tarafından farklı veri setleri ile yapılan çalışmada kurumlar ve gelir eşitsizliği arasında çift yönlü nedensellik tespit edilmiştir. Çalışmada bireysel olarak hükümet istikrarı, yolsuzluk, hukuk ve düzen, demokratik hesap verilebilirlik ve bürokratik kalitenin gelir eşitsizliği üzerindeki etkisinin yanında ayrıca söz konusu göstergelerin ortalaması alınıp kurumsal kalite etkisine de bakılmıştır. Elde edilen bulgularda kurumsal kalitenin gelir eşitsizliğini azalttığı tespit edilmiştir.

Gyimah-Brempong ve Camacho (2006), 21 OECD ülkesi için yaptıkları çalışmada yolsuzluktaki bir standart hatalık artışın gelir eşitsizliğini 0.05 oranında arttıracağına ulaşmıştır. Bu durum iktisadi büyüme üzerinden açıklanmakta olup, hızlı bir iktisadi büyümenin geliri arttırarak fakirliği ve yoksulluğu azalttığı ifade edilmektedir. Ancak yolsuzluğun varlığı durumunda fiziksel sermaye azalarak iktisadi büyüme yavaşlamakta bu da gelir eşitsizliğinin artmasına neden olmaktadır.

Carter (2006) çalışmasında ekonomik özgürlüklerin Gini katsayısını arttırdı̆̆ sonucuna ulaşmıştır. Ekonomik özgürlükler gelir elde edilmesinde çeşitli firsatları sunduğundan özellikle toplumdaki fakirler aleyhine gelir dağılımının bozulmasına neden olmaktadır. Tebaldi ve Mohan (2010)'ın çalışmasında ise yolsuzluk, kötü yönetim ve siyasi istikrarsızlığın gelir eşitsizliğinin artmasına yol açarak yoksulluğun artmasına neden olduğu belirtilmektedir.

Lin ve $\mathrm{Fu}$ (2016) ticaret ile gelir eşitsizliği arasındaki ilişkiyi demokrasi ile ilişkilendirerek incelemiştir. Buna göre demokrasi ile yönetilen toplumlarda ticari genişleme gelir eşitsizliğini arttırmaktayken, iktidarın tek elde toplandığı yönetim biçimlerinin olduğu toplumlarda ise ticari genişleme gelir eşitsizliğini azaltmaktadır. Bunun gerekçesinde ise demokratik toplumlarda daha gelişmiş bir iktisadi yapının (FDI, üretim, ihracat) varlığı 
gösterilmekteyken monarşilerde ise daha çok tarımsal faaliyetlerin var olması gösterilmektedir.

\section{OECD Ülkelerinde Gelir Eşitsizliğinin Gelişimi}

OECD ülkelerinde son 30 yılda gelir eşitsizliğinin değişimi 1985 yılı baz alınarak Şekil 1'de verilmiştir.

Şekil: 1

OECD Ülkelerinde Gelir Eşitsizliğinin Gelişimi

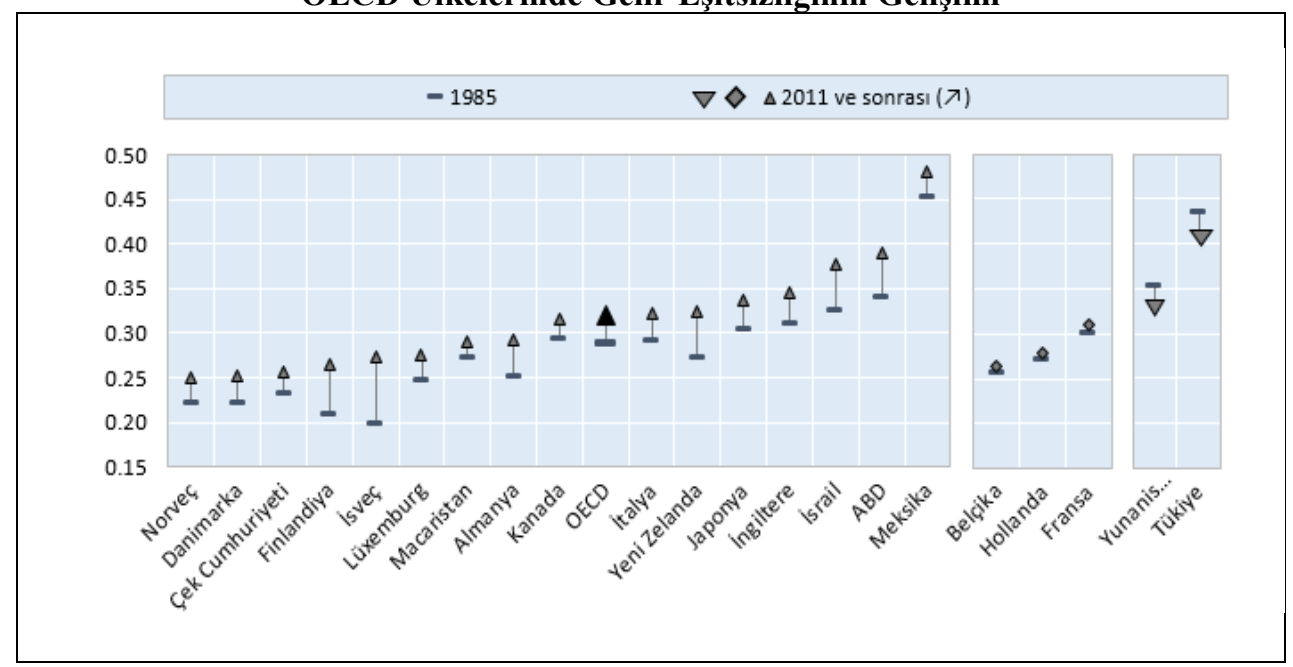

Kaynak: OECD, <http://www.oecd.org/social/inequality-and-poverty.htm>, 25.02.2016.

Şekil 1 incelendiğinde birçok OECD ülkesinde 1985 y1lından itibaren gelir eşitsizliğinin arttığı görülmektedir. Gini katsayısının çok küçük bir değişim gösterdiği ülkeler Belçika, Hollanda ve Fransa'dır. Yunanistan ve Türkiye'de ise gelir eşitsizliğine ilişkin olumlu bir gelişimin yaşandığı gözlenmektedir.

Son 30 yılda birçok OECD ülkesinde en zengin ile en fakir arasındaki fark 30 kat artmıștır. Günümüzde OECD ülkelerinde nüfusun en zengin \%10'u ile en fakir \%10'u arasındaki fark 8.5 kat iken söz konusu oran 1980'lerde 7 kat olarak gerçekleşmiştir (Cingano, 2014: 6). Son yıllarda OECD ülkelerine ait Gini katsayısı göstergeleri ile nüfusa göre gelirin dağılımı Tablo 1'de verilmiştir. 
Tablo: 1

OECD Ülkelerinde Gelir Eşitsizliği

\begin{tabular}{|c|c|c|c|c|c|c|c|c|c|}
\hline & \multicolumn{3}{|c|}{ Gini Katsayısı } & \multicolumn{6}{|c|}{ Gelirin Dağılımı (2013 veya sonrasında mevcut yıl) } \\
\hline Ülkeler & 2007 & 2011 & $\begin{array}{c}2013 \text { (veya } \\
\text { sonrası) }\end{array}$ & $\begin{array}{c}\text { En düşük } \\
\% 10\end{array}$ & $\begin{array}{c}\text { En düşük } \\
\% 20\end{array}$ & $\begin{array}{c}\text { En düşük } \\
\% 40\end{array}$ & $\begin{array}{c}\text { En yüksek } \\
\% 40\end{array}$ & $\begin{array}{c}\text { En yüksek } \\
\% 20\end{array}$ & $\begin{array}{c}\text { En yüksek } \\
\% 10\end{array}$ \\
\hline Avustralya & 0.34 & .. & 0.33 & 2.8 & 7.2 & 19.7 & 63.0 & 39.8 & 24.4 \\
\hline Avusturya & 0.28 & 0.28 & 0.28 & 3.1 & 8.5 & 22.6 & 59.2 & 36.0 & 21.6 \\
\hline Belçika & 0.28 & 0.27 & 0.27 & 3.6 & 8.8 & 22.6 & 58.8 & 35.2 & 20.8 \\
\hline Kanada & 0.32 & 0.31 & .. & 2.8 & 7.6 & 20.4 & 62.2 & 39.1 & 24.2 \\
\hline Şili & 0.51 & 0.50 & .. & 1.5 & 4.3 & 12.5 & 75.3 & 56.4 & 40.9 \\
\hline Çek C. & 0.25 & 0.26 & 0.26 & 4.0 & 9.9 & 24.3 & 58.0 & 35.7 & 21.7 \\
\hline Danimarka & 0.25 & 0.25 & 0.25 & 4.0 & 9.8 & 24.3 & 57.3 & 34.5 & 20.8 \\
\hline Estonya & 0.32 & 0.33 & 0.34 & 2.6 & 7.0 & 19.0 & 64.2 & 40.9 & 25.0 \\
\hline Finlandiya & 0.27 & 0.26 & 0.26 & 3.9 & 9.4 & 23.6 & 58.3 & 35.5 & 21.5 \\
\hline Fransa & 0.29 & 0.31 & 0.31 & 3.4 & 8.5 & 21.8 & 61.3 & 39.5 & 25.3 \\
\hline Almanya & 0.29 & 0.29 & 0.29 & 3.6 & 8.8 & 22.4 & 60.2 & 37.8 & 23.5 \\
\hline Yunanistan & 0.33 & 0.34 & 0.34 & 2.0 & 6.4 & 18.8 & 63.6 & 40.3 & 25.1 \\
\hline Macaristan & 0.27 & 0.29 & 0.29 & 3.1 & 8.3 & 22.0 & 60.2 & 37.0 & 22.5 \\
\hline İzlanda & 0.29 & 0.26 & 0.26 & 3.8 & 9.6 & 24.0 & 57.9 & 35.2 & 21.3 \\
\hline İrlanda & 0.30 & 0.30 & 0.30 & 3.2 & 8.3 & 21.3 & 61.6 & 38.7 & 23.8 \\
\hline İsrail & 0.37 & 0.38 & 0.36 & 1.7 & 5.5 & 17.1 & 65.8 & 41.8 & 25.6 \\
\hline İtalya & 0.31 & 0.32 & 0.33 & 2.2 & 6.9 & 19.7 & 62.8 & 39.7 & 24.7 \\
\hline Japonya & 0.33 & 0.34 & .. & 2.3 & 6.5 & 18.9 & 63.7 & 40.0 & 24.4 \\
\hline G. Kore & 0.32 & 0.31 & 0.30 & 2.2 & 6.8 & 20.5 & 61.1 & 37.1 & 21.9 \\
\hline Lüksemburg & 0.28 & 0.28 & 0.30 & 3.4 & 8.5 & 21.6 & 61.1 & 38.7 & 24.2 \\
\hline Meksika & 0.47 & 0.47 & 0.48 & 1.2 & 3.9 & 12.5 & 73.9 & 52.9 & 36.7 \\
\hline Hollanda & 0.29 & 0.28 & 0.28 & 3.4 & 8.8 & 22.7 & 59.4 & 36.7 & 22.4 \\
\hline Y. Zelanda & 0.33 & 0.32 & 0.33 & 3.1 & 7.6 & 19.7 & 63.8 & 40.7 & 25.7 \\
\hline Norveç & 0.25 & 0.25 & 0.25 & 3.3 & 9.1 & 24.1 & 57.3 & 34.5 & 20.6 \\
\hline Polonya & 0.32 & 0.31 & 0.30 & 3.2 & 8.1 & 21.5 & 61.0 & 38.1 & 23.2 \\
\hline Portekiz & 0.36 & 0.34 & 0.34 & 2.6 & 7.0 & 19.5 & 63.7 & 41.1 & 25.9 \\
\hline Slovakya & 0.25 & 0.26 & 0.25 & 3.5 & 9.1 & 23.8 & 57.7 & 34.2 & 19.7 \\
\hline Slovenya & 0.24 & 0.25 & 0.25 & 3.7 & 9.2 & 23.9 & 57.4 & 34.2 & 20.0 \\
\hline İspanya & 0.33 & 0.34 & 0.33 & 2.1 & 6.5 & 19.0 & 63.7 & 40.1 & 24.4 \\
\hline İsveç & 0.26 & 0.27 & 0.27 & 3.5 & 8.7 & 22.7 & 59.0 & 36.1 & 21.9 \\
\hline İsviçre &.. & 0.29 & 0.28 & 3.5 & 8.7 & 22.4 & 59.8 & 37.3 & 23.2 \\
\hline Türkiye & 0.41 & 0.41 &.. & 2.1 & 5.6 & 16.0 & 69.0 & 47.4 & 31.7 \\
\hline İngiltere & 0.36 & 0.34 & 0.35 & 2.7 & 7.2 & 19.3 & 64.5 & 42.6 & 28.0 \\
\hline $\mathrm{ABD}$ & 0.38 & 0.39 & 0.40 & 1.6 & 5.2 & 16.0 & 68.2 & 45.5 & 30.0 \\
\hline OECD & 0.31 & 0.31 & 0.31 & 2.9 & 7.7 & 20.6 & 62.2 & 39.4 & 24.6 \\
\hline
\end{tabular}

Kaynak: OECD Income Distribution Database (IDD), <www.oecd.org/social/income-distribution-database.htm>, 25.02.2016.

Tablo 1 incelendiğinde 2013 yılı ve sonrasındaki dönemde gelir eşitsizliğinin en düşük olduğu ülkeler 0.25 Gini değeri ile Danimarka, Norveç, Slovakya ve Slovenya iken en yüksek olduğu ülke ise 0.48 Gini değeri ile Meksika'dır. OECD ülkelerinde söz konusu döneme ilişkin gelir eşitsizliği ortalaması ise 24.6 olarak gerçekleşmiştir.

OECD ülkelerindeki gelir dağılımındaki bozulmada fakir nüfusun gelirinde yaşanan yavaş artışa karşın zengin nüfusun gelirinde yaşanan hızlı artış etkili olmakla birlikte ayrıca nüfusun yaşlanması, bekar-yetişkin hane halklarının sayısal artışı, tam zamanlı işçilerin kazançlarındaki artış (bunda küreselleşme, beceriye prim veren teknik değişim ve emek piyasası kurumları ve politikaları etkili olmuştur), eğitim düzeyi düşük olanlara yönelik istihdamın azalması, sermaye gelirlerinde ve serbest meslek gelirlerinin eşitsiz dağılımı da diğer sebepler arasında yer almaktadır (OECD, 2008: 17-18). Bu bağlamda OECD ülkelerinde gelir eşitsizliğinin artmasında etkili olan unsurlar üç grupta ele alınabilir (OECD, 
2011). Birincisi, küreselleşme, yeteneğe dayalı teknolojik gelişme, kurumsal ve düzenleyici reformlar, ikincisi; aile oluşumu ve hane halkı yapılarındaki değişim ve üçüncüsü ise devletin vergilendirme rejimi ve teşvik yapısıdır.

Gelir dağılımının iyileştirilmesinde devletin önemli bir görevi bulunmakta olup, bu bakımdan OECD ülkelerinde devlet müdahalesinin gelir eşitsizliğini azaltmada ne derecede başarılı olduğu sorusu da önem taşımaktadır. Bu bağlamda $23 \mathrm{OECD}^{1}$ ülkesinin ortalama Gini değerleri devlet müdahalesi öncesi ve sonrası olmak üzere Grafik 1'de verilmektedir.

Grafik: 1

\section{Devlet Müdahalesi Öncesi ve Sonrası Gelir Eşitsizliğinin Gelişimi}

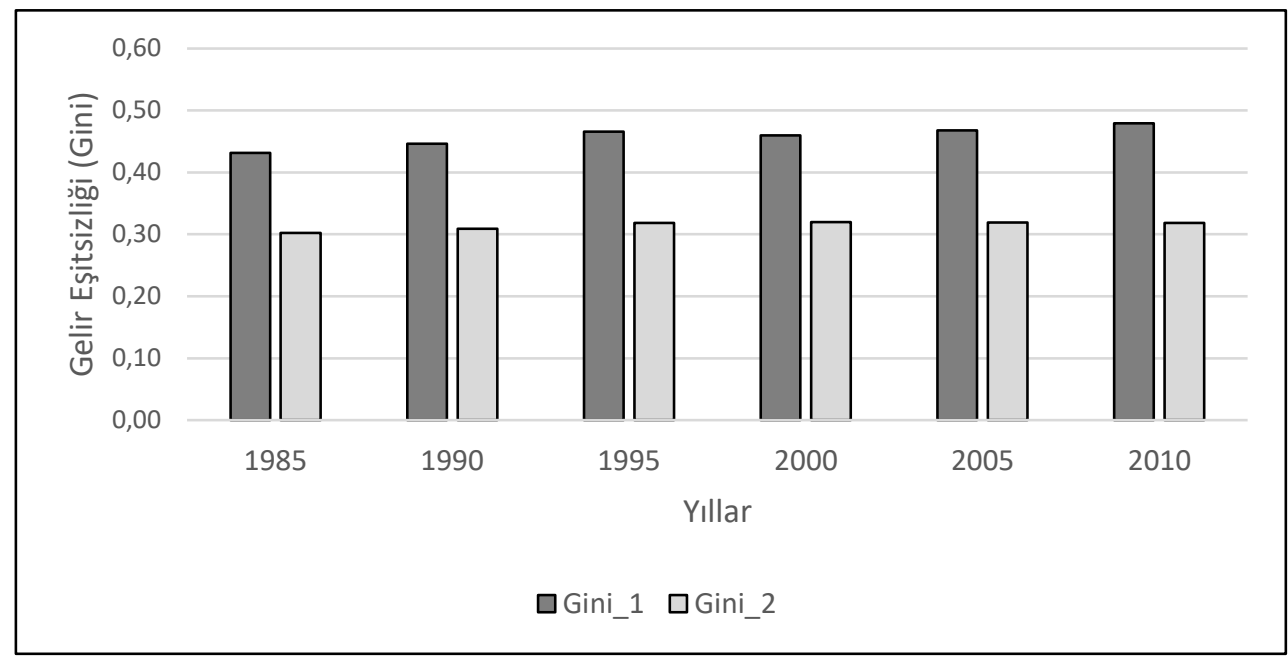

Kaynak: Solt, 2009'dan faydalanılarak oluşturulmuştur.

Grafik 1'de Gini_1 devlet müdahalesi olmadan piyasa sürecinde oluşan gelir eşitsizliğini, Gini_2 ise devlet müdahalesi sonrasında ortaya çıkan gelir eşitsizliğini ifade etmektedir. Yıllar itibariyle devletin transferler ve vergiler yoluyla müdahalesi gelir eşitsizliğini bir derece azaltmakla birlikte söz konusu etkinin bir noktanın ötesine geçemediği görülmektedir. Bir başka anlatımla müdahale sonrası Gini katsayısının yıllar itibariyle çok büyük bir değişiklik göstermediği ve 0.30 'lar seviyesine sabitlendiği ve daha aşağıya düşürülemediği ifade edilebilir.

1 Ülkeler: ABD, Avustralya, Avusturya, Belçika, Danimarka, Finlandiya, Fransa, G. Kore, Hollanda, İngiltere, İlanda, İspanya, İsveç, İsviçre, İtalya, Kanada, Meksika, Norveç, Portekiz, Şili, Türkiye, Y. Zelanda, Yunanistan. 


\section{Ekonometrik Analiz}

Çalışmada, kurumsal kalitenin gelir eşitsizliği üzerindeki etkisi veri mevcudiyeti çerçevesinde 23 OECD $^{2}$ ülkesi ve 1984-2011 dönemi için panel veri analizi ile araştırılmıştır. Bu bağlamda öncelikle yatay kesit bağımlılığın varlığ 1 araştırılmış ve buna göre birim kök testleri uygulanmıştır. Birim etkinin rassal ya da tesadüfi etkiler olduğuna ilişkin karar ise Hausman testi ile araştırılmış ve modelin sabit etkiler ile tahmin edilmesi gerektiği tespit edilmiştir. Baltagi (2005: 14)'ye göre bir grubu temsil eden ülkelerin tamamının analizde olmaması ve ülkelerin rassal olarak analize dahil edilmesi durumunda rassal etkili model ile tahminin yapılabileceği ifade edilmektedir. Bu bağlamda her ne kadar istatistiki test sonuçlarına göre sabit etkiler modelinin geçerli olduğu tespit edilse de sabit etkiler modeli yanı sıra rassal etkiler modeli ile de tahmin gerçekleştirilmiştir. Ayrıca varsayımlardan sapmalar araştırılmış ve modelin her iki tahmin yöntemi açısından da değişen varyans, otokorelasyon ve birimler arası yatay kesitliliğin varlığı altında tahmin edilmesi gerektiği sonucuna varılmıştır. Söz konusu sapmaların varlığında sabit etkili modeller için Driscoll-Kray; rassal etkili modeller için Parks-Kmenta dirençli tahmincisi ile model tahmin edilmiştir. Çalışmanın modeli aşağıdaki gibidir:

$$
\begin{aligned}
& \mathrm{GINI}_{\mathrm{it}}=\beta+\beta_{1} \mathrm{GDP}_{i t}+\beta_{2} \mathrm{INF}_{\text {it }}+\beta_{3} \mathrm{GOV}_{-} \mathrm{SIZE}_{\mathrm{it}}+\beta_{4} \mathrm{OPEN}_{\mathrm{it}}+\beta_{5} \mathrm{FDI}_{\mathrm{it}}+\beta_{6} \mathrm{INS}_{-} \mathrm{QUA}_{i \mathrm{it}}+\mu_{\mathrm{i}}+ \\
& \lambda_{\mathrm{t}}+\varepsilon_{\mathrm{it}}(\mathrm{i}=1, \ldots, \mathrm{n} ; \mathrm{t}=1 \ldots . \mathrm{t})
\end{aligned}
$$

Denklemde i ve t sırasıyla ülke ve zamanı, $\beta$ tahmin katsayılarını, $\mu_{i}$ ülke sabitini, $\lambda_{t}$ zaman sabitini ve $\varepsilon_{i t}$ ise hata terimini ifade etmektedir. Modeldeki değişkenler incelendiğinde GINI; Gini net katsayısının yüzdesel gösterimini, GDP; gayrisafi yurtiçi hasılanın büyüme oranını, INF; tüketici fiyat endeksi büyüme oranını, GOV_SIZE; kamu harcamalarının gayrisafi yurtiçi hasılaya oranını, OPEN; ihracat ve ithalat toplamının gayri safi yurt içi hasılaya oranını (ticari açıklığı), FDI; doğrudan yabancı yatırımların gayri safi hasılaya oranını ve INS_QUA ise kurumsal kaliteyi ifade etmektedir.

GINI verisi Solt (2009) tarafından geliştirilen SWIID veri tabanından, INS_QUA verisi International Country Risk Guide (ICRG)'ın sunmuş olduğu Politik Risk Bileşenleri (Political Risk Components) veri setinden, diğer veriler ise Dünya Bankası WDI veri tabanından elde edilmiştir. Çalışmada temel varsayım kurumsal kalitenin gelir eşitsizliği üzerinde negatif bir etkisinin olduğudur. Modelde yer alan diğer değişkenler ise kontrol değişken olarak alınmıştır.

Kurumsal kalite verisi; hükümet istikrarı, sosyoekonomik şartlar, yatırım profili, içsel çatışmalar, dışsal çatışmalar, yolsuzluk, siyasette askeri yaptırım düzeyi, dinsel çatışmalar, hukuk ve düzen, etnik çatışmalar, demokratik sorumluluk ve bürokratik kalite olmak üzere

2 Söz konusu ülkeler: ABD, Avustralya, Avusturya, Belçika, Danimarka, Finlandiya, Fransa, G. Kore, Hollanda, İngiltere, İrlanda, İspanya, İsveç, İsviçre, İtalya, Kanada, Meksika, Norveç, Portekiz, Şili, Türkiye, Y. Zelanda, Yunanistan. 
12 alt bileşenin toplamından oluşmaktadır. Söz konusu bileşenlerin toplamı maksimum 100 puan olmakta ve 100'e doğru gidildikçe daha yüksek kurumsal kaliteden bahsedilmektedir.

Modelde yer alan değişkenlere ilişkin tanımlayıcı istatistikler Tablo 2'de gösterilmektedir:

Tablo: 2

Tanımlayıcı İstatistikler

\begin{tabular}{lccccc}
\hline Değişken & Gözlem & Ortalama & Standart Sapma & Minimum & Maksimum \\
\hline GINI & 644 & 31.408 & 7.006 & 20.277 & 50.609 \\
GDP & 644 & 2.861 & 2.837 & -8.863 & 12.277 \\
INF & 644 & 6.680 & 14.018 & -4.500 & 131.800 \\
GOV_SIZE & 644 & 18.026 & 4.494 & 7.515 & 28.064 \\
OPEN & 644 & 66.971 & 30.194 & 16.574 & 178.253 \\
FDI & 644 & 3.319 & 6.286 & -5.695 & 88.096 \\
INS_QUA & 644 & 80.571 & 9.301 & 43.500 & 97.000 \\
\hline
\end{tabular}

Tablo 2 incelendiğinde 23 OECD ülkesi için 1984-2011 döneminde Gini katsayısının ortalaması 31.408 olarak gerçekleşmiştir ${ }^{3}$. Kurumsal kalite açısından incelendiğinde ise ortalamanın 80.571 olarak gerçekleştiği görülmektedir ${ }^{4}$. Bu oran OECD ülkelerinin genel olarak iyi bir kurumsal kaliteye sahip olduğunu ifade etmektedir. Söz konusu dönem aralığında Gini katsayısı değerinin en düşük olduğu ülke 20.27 ile İsveç iken en yüksek olduğu ülke ise 50.60 ile Şili'dir. Kurumsal kalite açısından değerlendirildiğinde ise en düşük değer 43.5 ile Türkiye'ye ait iken en yüksek değer ise 97 değeri ile İsviçre'ye aittir.

Modelde yer alan değişkenlerin korelasyon katsayılarını gösteren matris ise Tablo 3'de sunulmaktadır.

Tablo: 3

Korelasyon Matrisi

\begin{tabular}{lccccccc}
\hline & GINI & GDP & INF & GOV_SIZE & OPEN & FDI & INS_QUA \\
\hline GINI & 1.000 & & & & & & \\
GDP & 0.194 & 1.000 & & & & & \\
INF & 0.430 & 0.045 & 1.000 & & & & \\
GOV_SIZE & -0.720 & -0.357 & -0.407 & 1.000 & & \\
OPEN & -0.364 & 0.012 & -0.252 & 0.247 & 1.000 & & \\
FDI & -0.076 & 0.029 & -0.113 & 0.127 & 0.496 & 1.000 & \\
INS_QUA & -0.616 & -0.147 & -0.592 & 0.481 & 0.376 & 0.146 & 1.000 \\
\hline
\end{tabular}

3 Orijinal Gini katsayısı 0 ile 1 arasında değer almakta olup, 1 'e doğru gidildikçe gelir eşitsizliği artmaktadır. Çalışmada ise 0 ile 100 arasında gösterim kullanılmıştır.

4 Politik risk değerlendirmesinde; 0-49.9 puan arası çok yüksek politik riski, 50-59 puan arası yüksek politik riski, 60-69.9 arası orta düzey politik riski, 70-79.9 arası düşük politik riski ve 80 ve üzeri değerler ise çok düşük politik riski ifade etmektedir. 
Tablo 3 incelendiğinde kurumsal kalite ile gelir eşitsizliği arasında negatif bir korelasyonun varlığı görülmektedir. Buna göre kurumsal kalite arttığında gelir eşitsizliği azalmaktadır. Kontrol değişkenler açısından incelendiğinde büyüme ve enflasyon ile gelir eşitsizliği arasında pozitif bir korelasyon söz konusu iken, kamu hacmi, ticari açıklık ve doğrudan yabancı yatırımlar ile gelir eşitsizliği arasında ise negatif bir korelasyon söz konusudur.

Birim kök testine geçmeden önce serilerde ve modelde yatay kesit bağımlılık test edilmelidir. Yatay kesit bağımlılığın varlığı; T $>$ N olduğundan CD LM1 (Berusch Pagan, 1980) testi ile araştırılmış ve elde edilen bulgular Tablo 4'de verilmiştir.

Tablo: 4

Yatay Kesit Bağımlıık Test Sonuçları (CD LM1Test)

\begin{tabular}{lcc}
\hline Test & İstatistik Değeri & Olasillk Değeri \\
\hline GINI & 1430.160 & 0.000 \\
GDP & 402.529 & 0.000 \\
INF & 1758.488 & 0.000 \\
GOV_SIZE & 1094.645 & 0.000 \\
OPEN & 1492.314 & 0.000 \\
FDI & 1040.467 & 0.000 \\
INS_QUA & 1327.880 & 0.000 \\
MODEL & 2985.906 & 0.000 \\
\hline
\end{tabular}

Tablo 4 incelendiğinde seriler ve model için "yatay kesit bağımlılık yoktur" şeklinde ifade edilen $\mathrm{H}_{0}$ hipotezi reddedilmiştir. Buna göre paneli oluşturan ülkeler arasında yatay kesit bağımlılığın olduğu sonucuna varılmaktadır. Buna göre herhangi bir ülkede meydana gelen bir şok diğerlerini de etkilemektedir.

Serilerin durağan olup olmadıklarına karar verebilmek için yatay kesit bağımlılığı dikkate alan ikinci nesil birim kök testlerinin uygulanması gerekmektedir. Bu bağlamda CADF birim kök test sonuçlarına ilişkin bilgi Tablo 5'de yer almaktadır.

Tablo: 5

Birim Kök Testi-CADF

\begin{tabular}{|c|c|c|c|}
\hline Değişken & t-bar & $Z$ (t-bar) & p \\
\hline GINI & -2.185 & -2.130 & $0.017 * *$ \\
\hline GDP & -2.203 & -2.218 & $0.013^{* *}$ \\
\hline INF & -2.473 & -3.537 & $0.000^{*}$ \\
\hline GOV_SIZE & -1.659 & 0.447 & 0.673 \\
\hline OPEN $\overline{\mathbf{N}}$ & -1.952 & -0.988 & 0.161 \\
\hline FDI & -1.983 & -1.141 & 0.127 \\
\hline INS_QUA & -2.545 & -3.891 & $0.000 *$ \\
\hline$\Delta G \overline{O V}$ SIZE & -2.144 & -1.930 & $0.027 * *$ \\
\hline$\triangle O P E \bar{N}$ & -2.389 & -3.126 & $0.001 *$ \\
\hline$\Delta$ FDI & -3.437 & -8.256 & $0.000 *$ \\
\hline
\end{tabular}

Tabloda *,***** sırasıly 0.01, 0.05 ve 0.10 anlamlllık düzeylerini göstermektedir. 
CADF birim kök test sonuçları incelendiğinde GOV_SIZE, OPEN ve FDI serilerinin I(1)'de durağan oldukları görülmektedir. Bu nedenle söz konusu serilerin farkları alınarak seri durağanlaştırılmıştır.

Varsayımlardan sapmalar dikkate alınarak sabit etkiler modeli Driscoll-Kray dirençli tahminci ile ve rassal etkiler modeli ise Parks-Kmenta dirençli tahmincisi ile tahmin edilmiştir. Model tahminlerine ilişkin sonuçlar Tablo 6'da verilmiştir.

Tablo: 6

Tahmin Sonuçları

\begin{tabular}{|c|c|c|c|}
\hline \multicolumn{4}{|c|}{ Bağımlı Değişken: GINI } \\
\hline $\begin{array}{l}\text { Bağımsız } \\
\text { Değişkenler }\end{array}$ & $\begin{array}{l}\text { Sabit Etkiler Modeli } \\
\text { (Driscol-Kraay Dirençli } \\
\text { Tahmincisi) }\end{array}$ & $\begin{array}{l}\text { Bağımsız } \\
\text { Değișkenler }\end{array}$ & $\begin{array}{l}\text { Rassal Etkiler Modeli } \\
\text { (Parks-Kmenta Dirençli } \\
\text { Tahmincisi) }\end{array}$ \\
\hline GDP & $\begin{array}{l}0.340 \\
(0.029)^{* *}\end{array}$ & GDP & $\begin{array}{l}0.259 \\
(0.000)^{*}\end{array}$ \\
\hline INF & $\begin{array}{l}0.053 \\
(0.049) * *\end{array}$ & INF & $\begin{array}{l}0.082 \\
(0.000) *\end{array}$ \\
\hline$\triangle G O V \_S I Z E$ & $\begin{array}{l}0.636 \\
(0.231)\end{array}$ & $\triangle G O V \_S I Z E$ & $\begin{array}{l}0.422 \\
(0.103)\end{array}$ \\
\hline$\triangle O P E N$ & $\begin{array}{l}0.001 \\
(0.980)\end{array}$ & $\triangle O P E N$ & $\begin{array}{l}-0.015 \\
(0.615)\end{array}$ \\
\hline$\Delta$ FDI & $\begin{array}{l}-0.027 \\
(0.195)\end{array}$ & $\Delta$ FDI & $\begin{array}{l}-0.011 \\
(0.615)\end{array}$ \\
\hline INS_QUA & $\begin{array}{l}-0.402 \\
(0.000)^{*}\end{array}$ & INS_QUA & $\begin{array}{l}-0.246 \\
(0.000) *\end{array}$ \\
\hline SABİT & $\begin{array}{l}62.565^{*} \\
(0.000)\end{array}$ & SABİT & $\begin{array}{l}49.606^{*} \\
(0.000)\end{array}$ \\
\hline $\mathbf{R}^{2}$ & 0.39 & $\begin{array}{l}\text { Wald } \\
\text { Kikare }\end{array}$ & $\begin{array}{l}390.06 \\
(0.000)\end{array}$ \\
\hline F $(\mathbf{6}, 26)$ & $\begin{array}{l}590.89 \\
(0.000)\end{array}$ & Gözlem Sayısı & 621 \\
\hline Hausman Testi & $\begin{array}{l}13.09 \\
(0.041)\end{array}$ & & \\
\hline $\begin{array}{l}\text { Değiştirilmiş Wald } \\
\text { Testi }\end{array}$ & $\begin{array}{l}427.36 \\
(0.000)\end{array}$ & & \\
\hline $\begin{array}{l}\text { Bhargava vd. D-W } \\
\text { Testi }\end{array}$ & 0.122 & & \\
\hline $\begin{array}{l}\text { Baltagi-Wu LBI } \\
\text { Testi }\end{array}$ & 0.276 & & \\
\hline Gözlem Sayısı & 621 & & \\
\hline
\end{tabular}

Tabloda *,**,*** siraslyla 0.01, 0.05 ve 0.10 anlamlılık düzeylerini göstermektedir.

Tablo 6, sabit ve rassal etkiler ile tahmin edilmiş model sonuçlarını birlikte vermektedir.

Sabit etkiler ile tahmin sonuçlarına göre kurumsal kalite beklendiği gibi gelir eşitsizliğini azaltıcı bir etkiye sahiptir. Katsayı işareti beklendiği gibi olup anlamlıdır. Kurumsal kalitedeki bir birimlik artış gelir eşitsizliğini 0.40 birim azaltmaktadır. Buna göre kurumsal kalitenin iyileşmesi gelir eşitsizliğini azaltmakta ve gelirin daha eşit paylaşıldığı bir yapıyı ortaya çıkarmaktadır. Öte yandan kontrol değişkenler açısından incelendiğinde ise 
büyüme oranı ile enflasyon oranının da istatistiki olarak anlamlı olduğu görülmektedir. Büyüme katsayısı pozitif iken enflasyon katsayısı ise negatiftir. Enflasyonun katsayı işareti teorik beklenti ile uyumludur. Büyüme ile gelir eşitsizliği arasındaki ilişkide ise teoride katsayının pozitif ve negatif olduğu dönemler söz konusu olup, özellikle Kuznets'in açıkladığı gibi sanayileşme sürecinde gelir eşitsizliğinin büyümeden olumsuz etkilendiği bilinmektedir. Bu bağlamda analiz sonuçlarında büyümenin gelir eşitsizliğini arttırıcı bir etkisinin olduğu görülmektedir. Kamu hacmi, doğrudan yabancı yatırımlar ve ticari açıklığın gelir dağılımı üzerindeki etkisine ilişkin bulgular ise anlamsızdır.

Rassal etkiler ile model tahmin sonuçları incelendiğinde ise yine kurumsal kalitenin gelir eşitsizliği üzerinde azaltıcı bir etkiye sahip olduğu tespit edilmiştir. Sonuca göre kurumsal kalitedeki bir birimlik artış gelir eşitsizliğini 0.24 birim azaltmaktadır. Kurumsal kalite değişkenin katsayısı beklentilere uygun ve istatistiki olarak anlamlıdır. Elde edilen bulgular sabit etkiler modelinde elde edilen tahmin sonuçlarını teyit etmekte ve daha yüksek bir kurumsal yapı, gelirin daha eşit paylaşılmasına imkân tanımaktadır. Kontrol değişkenler incelendiğinde ise yine gelir büyüme oranı ve enflasyon oranının katsayısı anlamlı ve teorik beklenti ile uyumludur. Kamu hacmi, doğrudan yabancı yatırımlar ve ticari açıklığın gelir eşitsizliği üzerindeki etkisine ilişkin bulgular ise istatistiki olarak anlamlı değildir.

\section{Sonuç}

Gelirin eşit dağılmaması, günümüzün önemli iktisadi sorunlardan birisi olarak görülmektedir. Başta bireysel özellikler olmak üzere ekonomik, sosyal ve siyasi pek çok faktörün gelir eşitsizliği üzerinde etkisi bulunmaktadır. Son yıllarda ise söz konusu faktörlerin yanı sıra ülkelerin kurumsal yapısının gelir eşitsizliği üzerindeki etkisini ele alan çalışmalar ön plana çıkmaktadır. Bu alanda yapılan çalışmalar incelendiğinde kurumların ülkelerin ekonomik performanslarındaki etkisi yanında gelir eşitsizliği üzerinde de etkili olduğu görülmekte ve kurumsal yapısı güçlü olan ülkelerde gelir eşitsizliğinin daha düşük olması beklenmektedir.

Gelirin eşit dağılmaması iktisadi, sosyal ve siyasi olmak üzere bazı sorunların ortaya çıkmasında etkili olabilir. Toplumsal huzurun bozulması, refah kayıpları, suç oranlarının artması ve siyasi istikrarın dahi bozulması gelir eşitsizliği ile yakından ilgilidir. Söz konusu sonuçları bakımından gelir dağılımının daha eşit bir şekilde gerçekleşmesine ihtiyaç duyulmaktadır. Bu nedenle kurumsal kalitenin iyileştirilmesi sosyo-ekonomik performansın iyileştirilmesi açısından önemli görülmektedir.

OECD ülkelerinde kurumsal kalitenin gelir eşitsizliği üzerindeki etkisinin araştırıldığı bu çalışmanın bulguları, ülkelerin kurumsal yapılarındaki olumlu gelişmenin gelir eşitsizliğini azaltacağını göstermektedir. Çalışmada; hükümet istikrarı, sosyoekonomik şartlar, yatırım profili, içsel çatışmalar, dışsal çatışmalar, yolsuzluk, siyasette askeri yaptırım düzeyi, dinsel çatışmalar, hukuk ve düzen, etnik çatışmalar, demokratik sorumluluk ve bürokratik kalite olmak üzere 12 alt bileşenin toplamından oluşan kurumsal kalite değişkenindeki iyileşmenin gelir eşitsizliğini azaltmaya yönelik olumlu etkisi literatürde yer alan diğer çalışmaların da sonuçlarını teyit ederek tespit edilmiştir. Buna göre kurumsal 
kalitenin iyileştirilmesi yönünde atılacak adımların gelir eşitsizliği sorunun çözülmesinde önemli bir katkı sağlaması beklenmektedir.

\section{Kaynaklar}

Abdullah, A. \& H. Doucouliagos \& E. Manning (2015), "Does Education Reduce Income Inequality? A Meta-Regression Analysis", Journal of Economic Surveys, 29(2), 301-316.

Acemoglu, D. \& S. Johnson \& J.A. Robinson (2005), "Institutions as a Fundamental Cause of LongRun Growth", Handbook of Economic Growth, in P. Aghion \& S.N. Durlauf (ed.) Volume IA, Elsevier, 385-472.

Acemoglu, D. (2009), Introduction to Modern Economic Growth, Princeton University Press: New Jersey.

Acemoğlu, D. (2003), “Cross-Country Inequality Trends”, The Economic Journal, 113(February), F121-F149.

Alderson, A.S. \& N. François (2002), "Globalization and the Great U-Turn: Income Inequality Trends in 16 OECD Countries", American Journal of Sociology, 107(5), 1244-1299.

Baltagi, B.H. (2005), Econometric Analysis of Panel Data, Third Edition, John Wiley \& Sons Ltd: England.

Barro, R.J. (2000), "Inequality and Growth in a Panel of Countries", Journal of Economic Growth, 5(March), 5-32.

Breusch, T.S. \& A.R. Pagan (1980), "The Lagrange Multiplier Test and Its Applications to Modelspecification Tests in Econometrics", Review of Economic Studies, 47(1), 239-253.

Carter, J.R. (2006), “An Empirical Note on Economic Freedom and Income Inequality”, Public Choice, 130, 163-177.

Chong, A. \& C. Calderon (2000), "Institutional Quality and Income Distribution", Economic Development and Cultural Change, 48(4), 761-786.

Chong, A. \& M. Gradstein (2004), "Inequality and Institutions", Inter-American Development Bank, Working Paper, No: 506, <http://www.iadb.org/res/publications/pubfiles/pubWP506.pdf>, 25.02.2016.

Cingano, F. (2014), “Trends in Income Inequality and its Impact on Economic Growth", OECD Social, Employment and Migration Working Papers, No. 163, OECD Publishing, http://dx.doi.org/10.1787/5jxrjncwxv6j-en.

Dincer, O.C. \& B. Gunalp (2008), "Corruption, income inequality and poverty in the United States", Nota di lavoro // Fondazione Eni Enrico Mattei: Global Challlenges, No. 54.2008, <http://hdl.handle.net/10419/53357>, 25.02.2016.

Dökmen, G. (2012), "Yolsuzlukların Vergi Gelirleri Üzerindeki Etkisi: Dinamik Panel Veri Analizi”, Doğuş Üniversitesi Dergisi, 13(1), 41-51.

Gregorio, J.D. \& L. Jong-Wha (2002), "Education and Income Inequality: New Evidence From Cross-Country Data", Review of Income and Wealth, 48(3), 395-416.

Gupta, S. \& D. Hamid \& T. Rosa-Alonso (2002), "Does Corruption Affect Icome Inequality and Poverty", Economics of Governance, 3, 23-45.

Gyimah-Brempong, K. \& S.M. Camacho (2008), "Corruption, Growth, and Income Distribution: Are there Regional Differences?", Economics of Governance, 7, 245-269. 
Gyimah-Brempong, K. (2002), "Corruption, economic growth and income inequality in Africa", Economics of Governance, 3, 183-209.

Hindriks, J. \& M. Keen \& A. Muthoo (1999), “Corruption, Extortion and Evasion”, Journal of Public Economics, 74, 395-430.

Johansson, C. (2013), “Corruption and Income Inequality”, Bachelor's Thesis in Economics, Jönköping International Business School, Jönköping University.

Kama, Ö. (2016), “Kurumlar, Kurallar ve Büyüme İlişkisi Üzerine,” İktisat ve Toplum, 64, 20-27.

Knack, S. \& P. Keefer (1995), "Institutions and Economic Performance: Cross-Country Tests Using Alternative Institutional Measures", Economics and Politics, 7(3), 207-227.

Kuznets, S. (1955), "Economic Growth and Income Inequality", The American Economic Review, 45(1), 1-28.

Li, H. \& L.C. Xu \& H. Zou (2000), “Corruption, Income Distribution and Growth”, Economics and Politics, 12(2), 155-182.

Lin, F. \& D. Fu (2016), “Trade, Institution Quality and Income Inequality”, World Development, 77, 129-142.

North, D.C. (1994), "Economic Performance Trough Time,” The American Economic Review, 84(3), 359-368.

North, D.C. (1990), Institutions, Institutional Change and Economic Performance, Cambridge University Press: USA.

OECD (2008), Growing Unequal? Income Distribution and Poverty in OECD Countries, OECD Publishing,

<http://www.oecd.org/els/soc/growingunequalincomedistributionandpovertyinoecdcountr ies.htm>, 25.02.2016.

OECD (2011), “An Overview of Growing Income Inequalities in OECD Countries: Main Findings, Divided We Stand: Why Inequality Keeps Rising”, OECD Forum on Tackling Inequality, Paris.

Olson, M. (1996), "Distinguished Lecture on Ekonomics in Government: Big Bills Left on The Sidewalk: Why Some Nations are Rich, and Others Poor", Journal of Economic Perspectives, 10(2), 3-24.

Perera, L.D.H. \& G.H.Y. Lee (2013), "Have Economic Growth and Institutional Quality Contributed to Poverty And Inequality Reduction in Asia?", Journal of Asian Economics, 27(August), 71-86.

Piketty, T. \& E. Saez (2014), "Inequality in the Long Run”, The Since of Inequality, 344(6186), 838843.

Rodrik, D. (1997), "TFPG Controversies, Institutions and Economic Performance in East Asia," NBER Working Paper, 5914, <http://www.nber.org/papers/w5914>, 25.02.2016.

Sala-i-Martin, X. (1997), "I Just Ran Four Million Regressions,” NBER Working Papers, 6252, <http://www.nber.org/papers/w6252>, 25.02.2016.

Shleifer, A. \& R.W. Vishny (1993), “Corruption”, The Quarterly Journal of Economics, 108(3), 599617.

Solt, F. (2009), “Standardizing the World Income Inequality Database”, Social Science Quarterly, 90(2), 231-242. 
Stiglitz, J. (2015), "Income Inequality and Economic Growth", <http://www8.gsb.columbia.edu/faculty/jstiglitz/sites/jstiglitz/files/Inequality\%20and\%2 0Economic\%20Growth.pdf>, 25.02.2016.

Sylwester, K. (2000), "Income Inequality, Education Expenditures and Growth", Journal of Development Economics, 63, 379-398.

Tanzi, V. (1998), "Corruption Around the World: Causes, Consequences, Scope and Cures," IMF Working Paper Series, 63, <http://www.imf. org/external/pubs/ft/wp/wp9863.pdf>, 25.02.2016.

Teyyare, E. (2013), “Kriz, Kurumsal Kalite ve Ekonomik Büyüme İlişkisi”, Yayınlanmamış Doktora Tezi, Bülent Ecevit Üniversitesi Sosyal Bilimler Enstitüsü, Zonguldak.

Uğur, M. (2011), "Kurumsal Kalite ve Ekonomik Performans: İktisadın (Yeniden) Siyasallaşması mı?", Iktisat ve Toplum, 1(9), 36-41.

World Bank (2000), Making Transition Work for Everyone: Poverty and Inequality in Europe and Central Asia, The World Bank: USA.

Zhuang, J. \& E. Dios \& A. Lagman-Martin (2010), “Governance and Institutional Quality and the Links with Economic Growth and Income Inequality: With Special Reference to Developing Asia”, Asian Development Bank Economics Working Paper Series, 193. 